\title{
Ocular biometric characteristics during the menstrual cycle
}

\author{
This article was published in the following Dove Press journal: \\ Clinical Ophthalmology \\ 29 June 2015 \\ Number of times this article has been viewed
}

\author{
Harun Çakmak' \\ Ayten Taspinar ${ }^{2}$ \\ Mehmet Ozbagcivan' \\ Tolga Kocatürk' \\ 'Department of Ophthalmology, \\ ${ }^{2}$ Department of Midwifery, School of \\ Health, Adnan Menderes University \\ Medical Faculty, Aydın, Turkey
}

Purpose: To determine the ocular biometric characteristics during the menstrual cycle using the optical low-coherence reflectometry (OLCR) biometry.

Methods: Twenty-two healthy women between the ages of 19 and 36 years with regular menstrual cycles were enrolled in this prospective study. Subjects with irregular menstrual cycles, those taking contraceptive pills, those with a history of ocular surgery or trauma, and women unable to cooperate with the ocular biometry device were excluded from this study. A complete ophthalmic examination was performed between 8.30 and 10.30 am for all participants. Also, central corneal thickness, axial length, anterior chamber depth, lens thickness, and keratometric measurements were made at the same time using the OLCR device. Measurements were taken at the beginning of the cycle (1-3 days), at ovulation (12-16 days), and at the end of the cycle (26-32 days).

Results: The mean age of the participants was $22.86 \pm 4.22$ (range: $18-36$ ) years. The difference in central corneal thickness, axial length, anterior chamber depth, lens thickness, and keratometry values were not statistically significant during the menstrual cycle.

Conclusion: The ocular biometric parameters did not significantly vary during the menstrual cycle according to the OLCR biometry.

Keywords: ocular biometry, OLCR, menstrual cycle

\section{Introduction}

Sex steroid hormone receptors are located in various human ocular tissues, such as cornea, iris, ciliary body, lens, conjunctiva, retina, lacrimal and meibomian gland, in both males and females. ${ }^{1,2}$

Epidemiological studies show that sex hormones act differently according to sex and increase the incidence of age-related cataract, glaucoma, dry eye, neovascular age-related macular degeneration, central serous chorioretinopathy, etc. ${ }^{3-5}$

There are variations in the levels of the sex steroid hormones during the menstrual cycle. Thus, some researchers have shown that these hormone fluctuations show correlation with the ocular tissue variables. ${ }^{6,7}$ On the other hand, some researchers advocate that these fluctuations do not affect ocular variability significantly. ${ }^{8}$ The ocular biometric parameters may change during the different phases of the menstrual cycle.

Ciccone et $\mathrm{al}^{9}$ reported the importance of estrogens. They found that ophthalmic artery perfusion is increased after administration of intranasal 17-beta-estradiol in postmenopausal women.

The Lenstar LS 900 optical biometer is a device that is based on optical lowcoherence reflectometry (OLCR) technology. The Lenstar biometer measures central corneal thickness (CCT), anterior chamber depth (ACD), lens thickness (LT), axial length (AL), keratometry, pupil diameter, and white-to-white distance. ${ }^{10}$
Correspondence: Harun Çakmak Department of Ophthalmology, Adnan Menderes University Medical Faculty, Merkez Kampus Kepez Mevkii, 09100, Aytepe, Aydın, Turkey

Tel +905444400626

Fax +902562144086

Email dharuncakmak@gmail.com 
The aim of our study was to evaluate the ocular biometric characteristics during the menstrual cycle using the Lenstar LS 900 biometer.

\section{Methods}

Twenty-two healthy women between the ages of 19 and 36 years with regular menstrual cycles were enrolled in this prospective study. The study protocol was approved by Adnan Menderes University's ethics committee and complied with the tenets of the Declaration of Helsinki. Informed consent forms were completed and signed by all of the participants.

Subjects with irregular menstrual cycles, those taking contraceptive pills, those with a history of ocular surgery or trauma, and those unable to cooperate with the biometry device were excluded from this study. Subjects were asked to define the phases by counting forward the days from the start of menses.

A complete ophthalmic examination was done for all participants between 8.30 and $10.30 \mathrm{am}$. Also, biometric measurements (CCT, AL, ACD, LT, and keratometric values) were made at the same time using the OLCR device. Both eyes were measured, but only the right eye was taken to the study.

\section{Statistical analysis}

The appropriateness of the normal distribution of quantitative data was analyzed by the Kolmogorov-Smirnov test. Two-way analysis of variance for intergroup comparisons was used for normally distributed variables and descriptive statistics are shown as mean \pm standard deviation. For variables which were not in accordance with normal distribution, the Friedman test was used for intergroup comparisons, and descriptive statistics are shown in median (25th to 75 th percentile) format. $P<0.05$ was considered as statistically significant.

\section{Results}

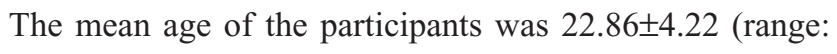
18-36) years. The mean CCT, AL, ACD, LT, and keratometric measurements (steep and flat keratometry readings) of the right eye are summarized in Table 1 (two-way analysis of variance). Measurements were made at the beginning of the cycle (1-3 days), at ovulation (12-16 days), and at the end of the cycle (26-32 days), on different menstrual cycle days, for 1 month (Table 2) (two-way analysis of variance).

The CCT and AL were thinnest at the beginning of the cycle and increased steadily until the end of the cycle, but
Table I The mean age and ocular biometric parameters

\begin{tabular}{lll}
\hline & Mean \pm SD & Minimum-maximum \\
\hline Age (years) & $22.86 \pm 4.22$ & $19-36$ \\
AL $(\mathrm{mm})$ & $23.47 \pm 0.88$ & $21.15-24.81$ \\
CCT $(\mu \mathrm{m})$ & $528.85 \pm 37.85$ & $452.33-589.67$ \\
ACD $(\mathrm{mm})$ & $3.60 \pm 0.29$ & $3.01-4.09$ \\
LT $(\mathrm{mm})$ & $3.47 \pm 0.18$ & $3.16-3.76$ \\
KI (diopter) & $43.82 \pm 1.65$ & $41.56-46.48$ \\
K2 (diopter) & $42.84 \pm 1.38$ & $40.18-45.10$ \\
\hline
\end{tabular}

Abbreviations: $A C D$, anterior chamber depth; $A L$, axial length; $C C T$, central corneal thickness; LT, lens thickness; KI, steep keratometry readings; K2, flat keratometry readings; SD, standard deviation.

these differences were not statistically significant $(P=0.498$ and $P=0.421$, two-way analysis of variance). Conversely, the LT was the thickest, and steep and flat keratometry readings were the highest, at the beginning of the cycle and decreased regularly at the end of the cycle $(P=0.179$, $P=0.892, P=0.434$, two-way analysis of variance). The ACD was reached the thickness value at the middle of the cycle (Table 2) (Friedman test).

\section{Discussion}

Changes in the anterior segment parameters during the menstrual cycle are referred to in the literature. Some researchers claim that these variations are significant, while others advocate that these differences are inconsiderable.

Giuffrè et al calculated corneal thickness during the menstrual cycle. They reported the cornea was thickest at the end of the cycle and thinnest at the beginning. ${ }^{11}$ On the other hand, Hashemi et al investigated corneal thickness, corneal curvature, and ACD during the menstrual cycle using the Scheimpflug imaging technique. ${ }^{12}$ They found no significant difference in measurements during the menstrual cycle period.

Corneal biomechanical parameters like corneal resistance factor and corneal hysteresis are determined by the ocular response analyzer. Goldich et al reported that corneal

Table 2 Measurements were made on three different menstrual cycle days for I month

\begin{tabular}{lllll}
\hline & $\begin{array}{l}\text { Menstrual } \\
\text { mean } \pm \text { SD }\end{array}$ & $\begin{array}{l}\text { Ovulatory } \\
\text { mean } \pm \text { SD }\end{array}$ & $\begin{array}{l}\text { Luteal } \\
\text { mean } \pm \text { SD }\end{array}$ & P-value \\
\hline $\mathrm{AL}(\mathrm{mm})$ & $23.46 \pm 0.89$ & $23.47 \pm 0.88$ & $23.48 \pm 0.87$ & 0.421 \\
$\mathrm{CCT}(\mu \mathrm{m})$ & $528.1 \pm 38.18$ & $528.64 \pm 37.88$ & $529.82 \pm 38.12$ & 0.498 \\
$\mathrm{ACD}(\mathrm{mm})$ & $3.07 \pm 0.27$ & $3.08 \pm 0.33$ & $3.07 \pm 0.29$ & 0.866 \\
$\mathrm{LT}(\mathrm{mm})$ & $3.49 \pm 0.19$ & $3.47 \pm 0.19$ & $3.44 \pm 0.21$ & 0.179 \\
$\mathrm{KI}($ diopter $)$ & $43.84 \pm 1.66$ & $43.83 \pm 1.65$ & $43.82 \pm 1.67$ & 0.892 \\
$\mathrm{~K} 2$ (diopter) & $42.86 \pm 1.36$ & $42.85 \pm 1.40$ & $42.82 \pm 1.40$ & 0.434 \\
\hline
\end{tabular}

Abbreviations: $A C D$, anterior chamber depth; AL, axial length; CCT, central corneal thickness; LT, lens thickness; KI, steep keratometry readings; K2, flat keratometry readings. 
resistance factor and corneal hysteresis decreased at the ovulation phase of the menstrual cycle. ${ }^{13}$ The CCT was thickest at the end of the cycle and thinnest at the beginning. ${ }^{13}$ Seymenoğlu et al determined corneal biometric properties during the menstrual cycle by using the ocular response analyzer. ${ }^{14}$ In contrast to Goldich et al's study, they could not find differences in corneal biomechanical properties and intraocular pressure during the menstrual cycle.

The Lenstar is an optical biometer that provides CCT, ACD, LT, AL, and keratometric measurements. The Lenstar uses the OLCR measurement principle and allows fast, comfortable, noncontact, less user-dependent, highly reliable, and reproducible measurements. ${ }^{15}$

Recently, Uçakhan et al compared the corneal curvature and ACD measurements using the Lenstar LS 900, Pentacam (Oculus, Wetzlar, Germany), and a manual keratometer in healthy eyes. ${ }^{16}$ The authors reported good correlation between the Lenstar and Pentacam for measuring the ACD and corneal curvature.

Another study, by Cruysberg et al evaluated the reproducibility of the Lenstar LS 900. ${ }^{17}$ The CCT and ACD measurements were compared between the Lenstar LS 900 and Visante AS-OCT. ACD and AL measurements, keratometric readings, and chamber depth measurements were compared between the Lenstar LS 900 and IOL Master. They found differences between the Lenstar LS 900, IOL Master, and Visante AS-OCT, and they did not recommend the use of these three optical devices interchangeably. On the other hand, they showed that the Lenstar LS 900 is an excellent reproducible optical biometric device for all reported measurements.

In our study, CCT, AL, ACD, LT, and keratometric values were found to change during the menstrual cycle. Some measurements were highest at the beginning of the cycle (LT and keratometric values), some measurements were highest at the middle of the cycle (ACD), and other measurements were highest at the end of the cycle (CCT and AL). However, none of these changes was clinically or statistically significant.

There are some limitation of our study. Firstly, small sample size is a limitation of the present study. Secondly, different phases of the menstrual cycle should be taken into consideration to avoid inconsistent results of changes in ocular variables. Lastly, we could not perform a multivariate regression model in order to evaluate the role of confounding factors (cardiovascular risk factors, the pharmacological history, etc) on results. Further studies with larger sample sizes with a multivariate regression model are needed.

\section{Conclusion}

Biometric measurement is important in refractive surgery calculation, in intraocular lens selection, prior to cataract surgery, for eyeglass or contact lens prescription, etc. Some biometric measurement devices are affected by hormonal influences during the menstrual cycle. The Lenstar LS 900 biometric measurement device is not affected by the variations of hormonal changes. Therefore, measurement with the Lenstar LS 900 can be used reliably in healthy women without reckoning with variations of hormonal changes during the menstrual cycle.

\section{Disclosure}

The authors report no conflicts of interest in this work.

\section{References}

1. Handa RJ, McGivern RF. Steroid hormones, receptors, and perceptual and cognitive sex differences in the visual system. Curr Eye Res. 2015; 40:110-127.

2. Gupta PD, Johar K Sr, Nagpal K, Vasavada AR. Sex hormone receptors in the human eye. Surv Ophthalmol. 2005;50(3):274-284.

3. Newman-Casey PA, Talwar N, Nan B, Musch DC, Pasquale LR, Stein JD. The potential association between postmenopausal hormone use and primary open-angle glaucoma. JAMA Ophthalmol. 2014 132(3):298-303.

4. Bigsby RM, Valluri S, Lopez J, et al. Ovarian hormone modulation of radiation-induced cataractogenesis: dose-response studies. Invest Ophthalmol Vis Sci. 2009;50(7):3304-3310.

5. Vingerling JR, Dielemans I, Witteman JC, Hofman A, Grobbee DE, de Jong PT. Macular degeneration and early menopause: a case-control study. BMJ. 1995;310(6994):1570-1571.

6. Versura P, Giannaccare G, Campos EC. Sex-steroid imbalance in females and dry eye. Curr Eye Res. 2015;40(2):162-175.

7. Versura P, Fresina M, Campos EC. Ocular surface changes over the menstrual cycle in women with and without dry eye. Gynecol Endocrinol. 2007;23(7):385-390.

8. Soni PS. Effects of oral contraceptive steroids on the thickness of human cornea. Am J Optom Physiol Opt. 1980;57(11):825-834.

9. Ciccone MM, Cicinelli E, Giovanni A, et al. Ophthalmic artery vasodilation after intranasal estradiol use in postmenopausal women. J Atheroscler Thromb. 2012;19(12):1061-1065.

10. Jasvinder S, Khang TF, Sarinder KK, Loo VP, Subrayan V. Agreement analysis of LENSTAR with other techniques of biometry. Eye (Lond). 2011;25(6):717-724.

11. Giuffrè G, Di Rosa L, Fiorino F, Bubella DM, Lodato G. Variations in central corneal thickness during the menstrual cycle in women. Cornea. 2007;26(2):144-146.

12. Hashemi H, Mehravaran S, Rezvan F. Changes in corneal thickness, curvature, and anterior chamber depth during the menstrual cycle. Can J Ophthalmol. 2010;45(1):67-70.

13. Goldich Y, Barkana Y, Pras E, et al. Variations in corneal biomechanical parameters and central corneal thickness during the menstrual cycle. J Cataract Refract Surg. 2011;37(8):1507-1511.

14. Seymenoğlu G, Baser EF, Zerdeci N, Gülhan C. Corneal biomechanical properties during the menstrual cycle. Curr Eye Res. 2011;36(5): 399-403. 
15. Huang J, McAlinden C, Su B, et al. The effect of cycloplegia on the lenstar and the IOLMaster biometry. Optom Vis Sci. 2012;89(12): 1691-1696.

16. Uçakhan ÖÖ, Akbel V, Bıyıklı Z, Kanpolat A. Comparison of corneal curvature and anterior chamber depth measurements using the manual keratometer, Lenstar LS 900 and the Pentacam. Middle East Afr J Ophthalmol. 2013;20(3):201-206.
17. Cruysberg LP, Doors M, Verbakel F, Berendschot TT, De Brabander J, Nuijts RM. Evaluation of the Lenstar LS 900 non-contact biometer. Br J Ophthalmol. 2010;94(1):106-110.

\section{Publish your work in this journal}

Clinical Ophthalmology is an international, peer-reviewed journal covering all subspecialties within ophthalmology. Key topics include: Optometry; Visual science; Pharmacology and drug therapy in eye diseases; Basic Sciences; Primary and Secondary eye care; Patient Safety and Quality of Care Improvements. This journal is indexed on

\section{Dovepress}

PubMed Central and CAS, and is the official journal of The Society of Clinical Ophthalmology (SCO). The manuscript management system is completely online and includes a very quick and fair peer-review system, which is all easy to use. Visit http://www.dovepress.com/ testimonials.php to read real quotes from published authors. 